International Journal of Stem Cell Research and Transplantation (1JST)

ISSN: 2328-3548

\title{
Cancer Stem- Like Cells in Melanoma Progression, Resistance and Recurrence: Significance for Melanoma Treatment
}

Review Article

Hassan $\mathrm{M}^{1,2,3^{*}}$, El Khattouti $\mathrm{A}^{1}$, Haikel $\mathrm{Y}^{2,3}$, Megahed $\mathrm{M}^{4}$

${ }^{1}$ Cancer Institute, University of Mississippi Medical Center, Jackson, MS 39216, USA.

${ }^{2}$ Institut National de la Santé et de la Recherche Médicale, U 977.

${ }^{3}$ Department of Operative Dentistry and Endodontics, Dental Faculty, University of Strasbourg, 67000 Strasbourg, France.

${ }^{4}$ Clinic of Dermatology, University Hospital of Aachen, Pauwelsstr. 30, 52074 Aachen, Germany.

Abstract
Human malignant melanoma is a highly aggressive tumor which demonstrates heterogeneity and a propensity to drug resistance.
Despite improved treatment options, patients with advanced malignant melanoma continue have a poor prognosis as measured by
progression-free and overall survival. The cancer stem-like cell (CSC) hypothesis suggests that neoplastic clones are maintained by a
small fraction of cells with stem cell properties. As has been demonstrated with other tumor types, melanoma progression, resistance
to chemo- and radiotherapy, and recurrence can be attributed to a small fraction of cells termed melanoma stem-like cells (MSCs).
These MSCs are characterized by a distinct protein patterns and aberrant signaling pathways, which are either in a causal or consequen-
tial relationship to tumor progression, drug resistance and recurrence. This review focuses on the mechanistic role of MSCs leading to
tumor progression and metastasis, resistance and recurrence. Understanding the molecular mechanisms underlying MSCs migration,
invasion, resistance to standard treatments, and recurrence may help to improve current therapeutic modalities and/or pave the way
for the development of new therapeutical management strategy for tumor treatment.

\section{*Corresponding Author:}

Mohamed Hassan,

Cancer Institute, University of Mississippi Medical Center, 2500 North

State Str., Jackson, MS 39 216, USA.

Tel: +1 601815 8945; Fax: +1 6019842981

E-mail: Dr.hassan@gmx.de

Received: June 16, 2014

Accepted: June 28, 2014

Published: June 30, 2014

Citation: Hassan M, et al. (2014). Cancer Stem- Like Cells in Melanoma Progression, Resistance and Recurrence: Significance for Melanoma Treatment, Int J Stem Cell Res Transplant, 02(04), 78-85. doi: http:// dx.doi.org/10.19070/2328-3548-1400013

Copyright: Hassan $\mathbf{M}^{\odot}$ 2014. This is an open-access article distributed under the terms of the Creative Commons Attribution License, which permits unrestricted use, distribution and reproduction in any medium, provided the original author and source are credited.

\section{Introduction}

Like most healthy tissues, cancer stem cells are hierarchically organized at a cellular level and exist in the form of small fraction of subpopulations that are primarily responsible for tumor initiation, maintenance and propagation [1-3]. Accordingly, this small fraction of tumor subpopulation is characterized by its ability to drive prolonged maintenance and sustained self-renewal, a mechanism that is essential for tumor growth and differentiation $[4,5]$. This small fraction of subpopulation drives self-renewal through asymmetrical cell division to produce two daughter cells, one of them is potentially able to differentiate and ultimately forms the tumor mass, whereas the second one maintains its stemness properties so that can function as a CSC $[6,7]$.
The hypothesis of CSC suggests that neoplastic clones are maintained by a small fraction of cells with stem cell properties [8]. Cancers are thought to arise from stem cells and are expected to undergo the same progeny, differentiation and progression observed in normal tissues [9]. Tumor metastatic dissemination, resistance to chemo- and radiotherapy, and recurrence thought to be attributed to CSCs [10-12]. The treatment regimens of melanoma patients are of limited benefit, particularly, in advanced stages since available treatments can primarily target tumor bulk, but not MSCs [13]. The existence of MSCs phenotype has been confirmed in a small fraction of cells derived from either tumor biopsies or from established tumor cell lines [14-17]. These small fractions can form" melanoma spheroids" when allowed to grow in a specific stem cell medium[18] and exhibit self-renewal activity in vitro as well as in vivo [17-20]. Melanoma spheroids are able to differentiate into different cell types including, those of mesenchymal-lineage besides their tumorigenic potency when transplanted into immune-deficient mice [21,22]. MSCs are characterized by the expression of stem cell maker including, CD20, CD133, and CD166 [17], ABCB5 [23], CD146 [24], and Nestin [25]. More importantly, the increased expression of the self-renewal transcription factor, Bmi-1, in primary and metastatic tumors [26], is an evidence for CSCs potential in tumor progression, invasion and metastatic dissemination. The frequent tumor recurrence seems to result from the preferential killing of tumor bulk while leaving CSCs behind [27]. Although the development of effective therapeutic modalities against peculiar and multiple melanoma antigens still remains a crucial challenge, thus understanding the molecular mechanisms underlying MSCs migration, invasion, resistance to standard treatments and recurrence may help to improve current therapeutic modalities and/or pave the way for the development of new therapeutical management strategy for the tumor treatment. 
Malignant Melanoma Characteristics And Epidemiology

Human malignant melanoma is a highly metastatic cancer type that is substantially resistant to standard therapeutic modalities. Although the survival rate of melanoma patients has been improved over the past decades [28], melanoma risk and overall mortality escalate yearly [29] Generally, primary melanomas are curable by surgical excision when diagnosed early and thereby the number of patients with regional lymph node infiltrations can be decreased [30]. However, the prognosis of patients with visceral metastasis is very poor as evidenced by a median survival rate of only a few months [31]. Because of the therapeutic benefit of current treatment regimens in a significant portion of melanoma patients showing poor prognosis, the development of new therapeutic strategies is urgently needed.

The clinical classification of melanoma is based on the total thickness (in millimeters), the mitotic rate, the presence of ulceration, the depth of penetration, and metastatic location [32]. Whereas, the histological classification defines five distinct stages of melanoma progression including, benign nevi without dysplastic changes, dysplastic nevi, radial-growth phase (RGP), vertical growth phase (VGP), and metastatic melanoma [33].

Although melanoma is derived from melanocyte origin, there are diverse cell types that can be located within or surrounding melanoma lesions. These include endothelial cells, immune cells, keratinocytes, and fibroblasts. Thus, before initiating the malignant transformation, melanocytes start to intersperse among keratinocytes to form an epidermal melanin unit that can transfer melanin granules to the keratinocytes [34]. Whereas, keratinocytes , in turn, serve as the key regulators of early stage melanoma cell homeostasis and proliferation [35].

\section{Concept of cancer stem cells (CSC)}

The idea that cancer might originate in SC refers back to the $19^{\text {th }}$ century's concept of "embryonal rests" present in the adult [3639]. Over a century later, the similarity between the old belief that cancer arises from embryonal rests and the contemporary view that some forms of cancer originate in adult tissue-specific SC has revitalized when leukemia-initiating SC were reported in the peripheral blood of patients with acute myelogenous leukemia (AML) [40]. In the meantime, the presence of SC in breast cancer [41,42] , brain cancer [43], ovarian cancer [44], lung cancer [45], colon cancer [46,47], head and neck squamous cell cancer [48] and prostate cancer [49] has been reported. Also, CD20-positive subpopulation has been identified in melanoma [17]. CD20 is an integral membrane protein that is first detected on B-lymphocytes; and is involved in transmembrane calcium flux, and in cell-cycle progression [50]. CD20-positive melanoma cells can grow as nonadherent spheres in human embryonic growth medium, whereas in standard medium they can grow as adherent monolayers. Under appropriate culture conditions, cells from the non-adherent spheres could be differentiated into multiple cell lineages, such as melanocytic, adipocytic, osteocytic, and chondrocytic [51]. These melanoma spheroid cells have been shown to persist after serial cloning in vitro and transplantation in vivo, confirming their selfrenewal ability [17,52].

Accumulating evidence supports the existence and the involvement of CSCs in melanoma initiation, progression, chemoresistance, therapeutic failure and recurrence [17,53,54]. Like normal tissues, melanoma is composed of phenotypically heterogeneous cell populations [55]. Whereas, highly aggressive melanoma subpopulations are characterized by the expression of molecular signatures similar to those of pluripotent stem cells [24]. Thus, the expression of the stem cell markers such as, ABCB5, CD133, CD166, CD34, nestin, c-kit antigens, cancer testis antigens, bone morphogenetic protein (BMP), Notch receptors and Wnt proteins, in addition to their tumorigenic and differentiation potential has been reported in melanoma subpopulation derived from either patients biopsies or from established melanoma cells lines $[15,23,56]$. A proposed model for the possible mechanism of how cancer stem cells arise is outlined in Figure 1.

Figure 1. Proposed model of how a cancer stem cell does arise. An adult stem cell undergoes genetic and epigenetic alterations, as a consequence progenitor cell can develop to either normal progenitor cell or differentiated cell. The accumulation of a consequent serial of mutations can drive the fully differentiated cell back to gain stemness properties. The activation of self-renewal genes results in the development stem cells to cancer stem cell.

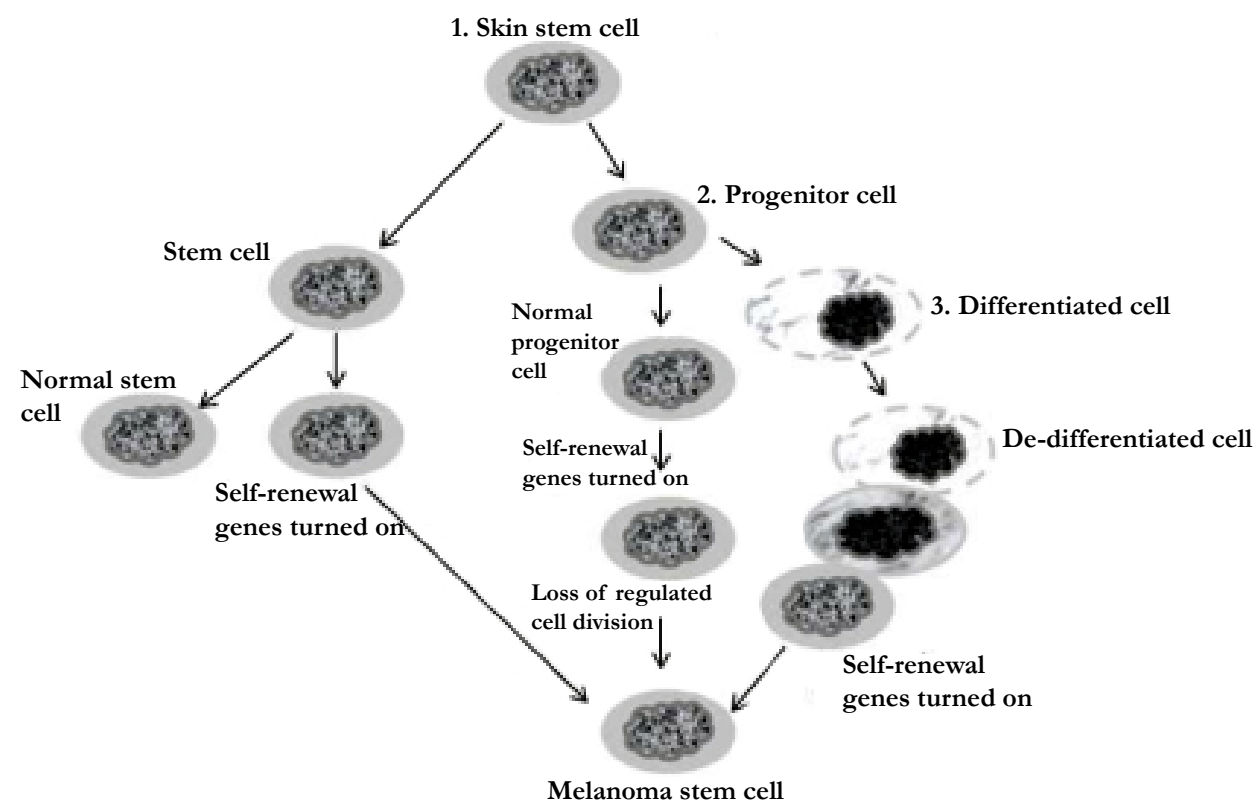


Mechanisms of Cancer Stem-Like Cells in Melanoma Progression and Metastasis

Metastasis is a process, whereby primary tumor disseminates to establish new tumor colonies at distant organ or tissue sites. This process is mediated through the migration into the lymphatic system and/ or .dissemination through the blood circulation $[57,58]$. Accordingly, melanoma is known to be a highly metastatic cancer among solid tumors [59]. Although the clinical significance of melanoma metastasis has been demonstrated, the cellular and molecular mechanisms underlying metastatic melanoma progression are not characterized in detail.

To understand the mechanisms of tumor metastasis, several models and theories have been proposed [60-62]. One of these models based on the clonal selection suggesting that the continuous accumulation of mutations together with the chromosomal imbalances may result in the development of cancerous cells with metastatic properties, particularly, in advanced stages of tumor. Whereas, the other model suggests that the tendency of tumor cells to metastasize thought to be determined in the early processes of tumorigenesis. This theory based on the identification of metastatic features in primary tumor cells or even their transformed precursors before the initiation with the neoplastic progression. Moreover, functional genomic studies revealed that limited subsets of tumor cells within the primary lesions are programmed to metastasize to specific organs $[63,64]$. Thus, in the context of CSC concept, it is plausible that these limited subsets of tumor cells/subpopulations may be attributed to CSCs, and thereby have the capacity to initiate tumor formation. Accordingly, some characteristics of the identified CSCs are identical with those of normal stem cells [65]. These stem cell properties are responsible for the mechanisms underlying metastatic process of cancer cells. Also, stromal cell niche or signaling pathways that function as key modulators of normal stem cell proliferation and migration have been shown to play an essential role in tumor cell invasion and dissemination [66,67]. Moreover, the components of cellular niche have been reported to provide anchoring sites for somatic stem cells. As well, the attachment of somatic stem cells to the anchoring sites is orchestrated through mechanisms mediated by distinct signaling molecules such as $\beta$-catenin, a downstream effector of Wnt signaling pathway $[68,69]$. Thus, excessive activation of the Wnt pathway is mainly associated with melanoma progression via mechanism mediated by the enhancement of the translocation of $\beta$-catenin to the nucleus [70]. The disruption of $\beta$-catenin/E-cadherin complexes has been shown to be causally linked to the breakdown of epithelial to mesenchymal transition (EMT) [72]. Thus, the most known key molecules that are associated with melanocyte stem cell maintenance and melanoma metastasis are Slug and Twist $[73,74]$. These proteins have been reported to play an essential role in the promotion of EMT and the induction of the transcriptional repressors of Ecadherin [75]. Accordingly, the crosstalk between Wnt signaling factors and the cadherin-catenin adhesion system is an essential mechanism that regulates the localization of normal and melanoma stem cells [76]. Also, other molecules such as integrins are involved in the local invasion of melanoma [77] and the regulation of matrix metalloproteinases [78]. Moreover, the melanoma

Figure 2. Proposed model for metastatic dissemination of Melanoma-initiating cells/melanoma stem-like cells (MSC). The circulation of MSC allows it to roll in the blood flow on microvascular endothelial cells of the metastatic target tissue. As a result the constitutively active MSC $\alpha 4 \beta 1$ integrin binds to the endothelial VCAM-1, and the E-selectin glycoprotein and glycolipid ligands of MCS bind to the endothelia E-selectin of microvascular endothelia cells. Also, the elevated $\alpha 5 \beta 1$ integrin on MSC can interacts with the endothelial ligand, fibronectin (FN). As consequence, the MSC becomes able to traverse endothelial cell-cell junction through $\alpha 5 \beta 1$ and the $\alpha 6 \beta 4$ binding to the surface and basement membrane ligands, Laminin (LN) and FN. The process of MCS migration is thought to involve the binding of IL-8 and SDF1 to CXCR1 and CXCR4, respectively. A mechanism that is described in migratory process of melanoma and CSCs. Also, additional factors such as VEGFR-1, VE-cadherin, and TIE may be involved in the promotion of MSC metastasis.

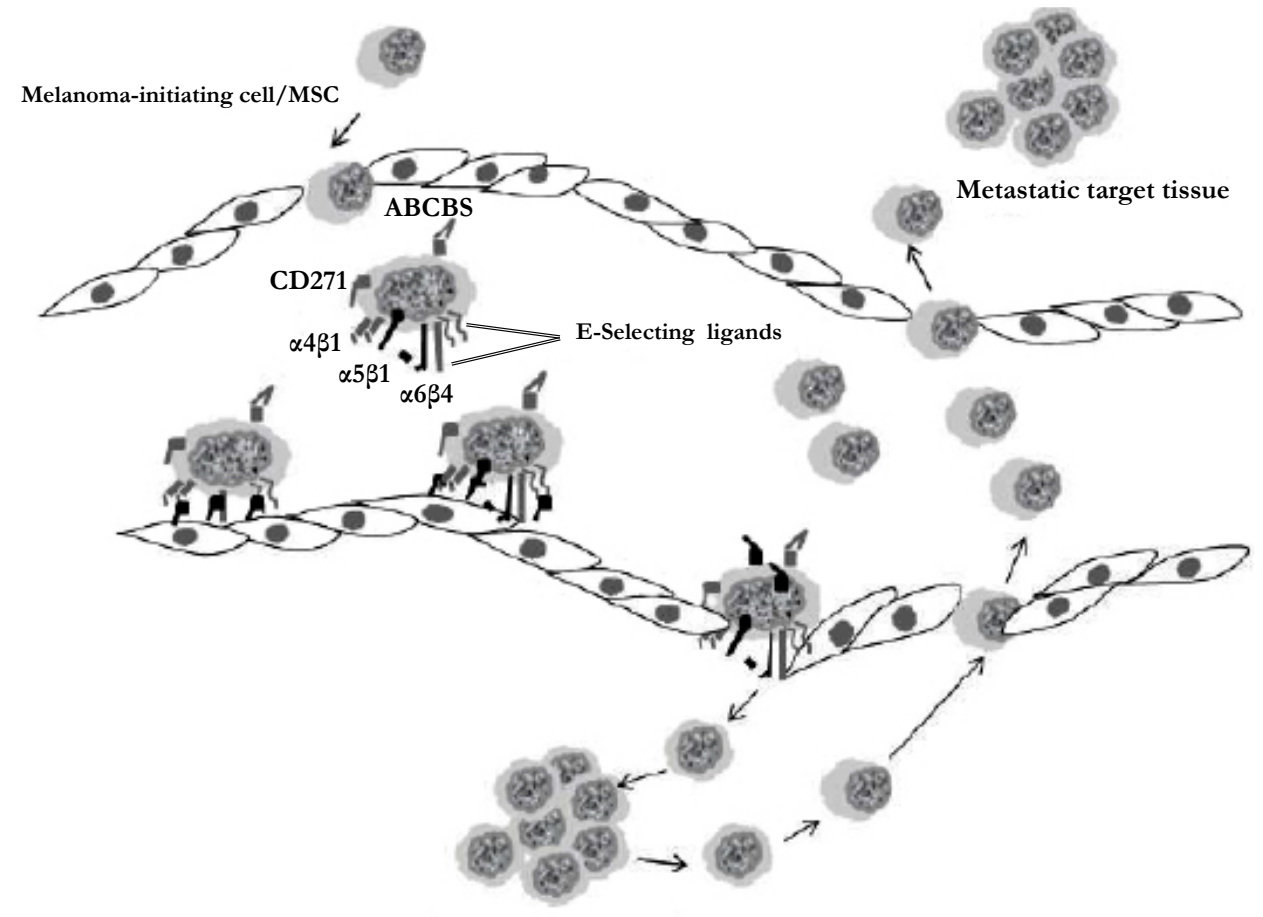

Metastatic target tissue 
metastasis gene, NEDD9 is required for melanoma cell invasion and dissemination. The expression of NEDD9 protein is elevated in patient biopsies and is associated with melanoma progression [79]. The detection of NEDD9 protein in $\mathrm{CD} 133^{+}$human cord blood progenitor cells under condition leading to the enhancement of metastatic potential of cancer cells, suggesting an essential role for this protein in the regulation of the metastatic potential of CSCs. Thus, during tumor progression CSCs hijack the mechanistic program of the epithelial-to-mesenchymal transition, releasing their epithelial characteristics, such as resistant cadherindependent junctions to gain the invasive ability [80]. The ability of normal and tumor cells to migrate is based on a common regulatory mechanisms, by which the stromal cell derived factor 1 (SDF1) signaling mediates the regulation of hematopoietic stem cells (HSCs) migration, via the $\mathrm{C}-\mathrm{X}-\mathrm{C}$ chemokine receptors type4 (CXCR4). Like other cancer types, the dissemination of melanoma subpopulation is mediated by SDF-1/CXCR4 system [81]. Thus, the inhibition of the interaction between CXCR4 and its ligand SDF-1 has been reported to suppress melanoma metastasis into murine lungs [81]. Of note, the elevation of CXCR4 levels is mostly associated with poor prognosis in patients with malignant

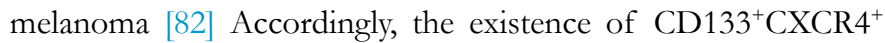
melanoma subpopulation in cutaneous melanomas with invasive phenotype and poor prognosis is an evidence for the functional role of SDF-1/CXCR4 system in the promotion of melanoma progression and migration, and finally the metastatic potential of MSCs. Proposed model for metastatic dissemination of Melanoma-initiating cells/ MSC is out lined in Figure.2.

\section{Mechanisms of Melanoma Stem-Like Cells- Me- diated Chemo- Resistance}

The chemo-resistance of advanced malignant melanoma is mediated by several mechanisms, which have been intensively studied in the context of tumor stem cell [83]. These resistance mechanisms include the destruction of cancer apoptotic pathways, excessive activation of aberrant signaling pathways leading to tumor growth and survival, induction of the expression of $\mathrm{ABC}$ drug efflux transporters $[84,85]$. ABCB5, is a human multi-drug resistance (MDR) P-glycoprotein family member, which mediates chemo-resistance in melanoma via its function as a drug efflux transporter $[86,87]$. The expression of ABCB5 is associated with increased level of tumor antigen P97, a melanotransferrin (MTf) that is associated with melanoma growth [88]. More importantly, the expression of ABCB5 has been shown to be specific to $\mathrm{CD} 133^{+}$tumor stem cell phenotype [14]. Also, immune histochemical analysis of clinical samples derived from patients with malignant melanomas showed that the expression of ABCB5 is characteristic for a minority of melanoma population of both primary and metastatic origin [89].

Because of CSCs are resistant to chemo- and radiation therapy, the failure of conventional therapy and thereby result in tumor relapse. Accordingly, tumor recurrence may be the consequence of the preferential killing of differentiated cells while leaving CSCs behind. Thus, understanding the mechanisms that underlying MSCs resistance may help improve the treatment outcome and, in turn, prevent melanoma recurrence.

Chemo-and radiation resistance of CSCs is mediated through genetic and cellular alterations conferring resistance to conventional therapeutic approaches [90,91]. Genetic and cellular alterations include, tumor dormancy associated with delayed cell cycle kinet- ics, efficient DNA repair, the expression of multidrug-resistance transporters, and destruction of the apoptotic pathway[92]. The role of checkpoint kinases $1 / 2(\mathrm{Chk} 1 / 2)$ in the modulation of CSCs resistance to chemo- and radiation therapy has been reported $[93,94]$. It has been reported that Chk $1 / 2$ kinases have higher basal and inducible activities in CSCs when compared to normal stem cells [95]. Although some therapeutics like alkylating agents have been approved for their cytotoxicity, these agents can also enhance Chk1/2 kinases in CSCs and thereby contribute to the potentiation of the resistance mechanisms of CSCs to chemoand radiation therapy [96]. Moreover, CSCs can deduce resistance to chemical agents through the expression of drug efflux pumps such as $\mathrm{ABC}$ family members, as a mechanism that responsible to pump the drugs out of the cells [97]. The expression of ABCB5 in CSCs including MSCs has been reported [98]. The role of Akt pathway in the modulation of CSCs resistance is also suggested [99]. Also, the expression of apoptotic inhibitors is a mechanism, whereby CSCs confer resistance to chemo-and radiation therapy.

\section{Mechanisms of Cancer Stem-Like Cells in Mela- noma Recurrence}

The ability of normal adult stem cells to maintain the balance between self-renewal and differentiation is mediated by adhesive factors and signaling interactions in stem cell niches. Thus, the mechanism regulating the entry of metastasis-initiating cells into dormancy and to undergo reactivation of key components of cancer stem niche $[100,101]$.

Melanoma recurrence is an important phenomenon, since the presence of persistent tumors in patients is important not only for clinical management, but also for understanding tumor biology, particularly tumor dormancy. Melanoma recurrence and dormancy seem to result from the inability of current therapeutic regimens to completely eradicate the putative melanoma subpopulation [102]. Although the recurrence risk is very low so that the need to invasive follow up beyond long time is not taken seriously, and new symptoms or clinical findings may go back to the earlier diagnosis.

Apart from clinical cause and features of melanoma recurrence, the balance between cell proliferation and apoptosis is thought to be an essential determinant of the melanoma tumorigenic potential. Although the proliferative activity of melanoma is regulated, in part, by tumor vascularity[103], the contribution of nonvascular extracellular matrix is also essential for tumor progression[104,105]. Accordingly, the role of MSCs is increasingly recognized in the progression of primary melanoma and its metastasis $[24,54]$. Accumulated evidence reveals that the cells that initiate metastatic outgrowth of CSCs are tumor cells with stem cell properties [54]. The antigenic patterns of primary melanoma are variable and heterogeneous, and possess small fraction of subpopulation that is characterized by the expression of CSC marker, such as CD166, CD133, and nestin [24], an evidence for the presence of genetic pathways that are instrumental for stem cell biology. As widely established metastasis-initiating cells are cancer stem cells, whose entry into dormancy and subsequent reactivation is mediated by intrinsic programs and signaling pathways that resemble the self-renewal mechanism of adult stem cells. Thus, many patients with carcinomas have been found to suffer from metastatic recurrence in later years after initial diagnosis and radically surgical and nonsurgical treatments [106,107]. 


\section{Mechanisms Regulating The Adhesion of Mela- noma Stem-Like Cells To Their Niches}

Normally, at least in the hematopoietic, intestinal, and hair follicle systems, the niche maintains SC primarily in a quiescent state by providing signals that inhibit cell growth as evidenced by the ability of SC to retain bromodeoxyuridine labeling for long periods of time [108] The function of niche cells is likely to block expression of genes that trigger the onset of differentiation with differentiation being the default stage (fail-safe mechanism). The proliferation of CSC needs depends on the reactivation of stem cell (SC) niche in response to CSC self-renewal signals. Alternatively, CSC or transient-amplifying progenitor cells have become niche-independent upon genetic or epigenetic alterations that enable autonomous self-renewal.

Cadherin and $\beta$-catenin adhesion molecules anchor melanocytes in the epidermis [109]. Epidermal SC remain attached to the niche through the cadherin- $\beta$-catenin interaction, while in the activated stage, $\beta$-catenin is localized to the nucleus, a mechanism that is essential for SC proliferation to ensue [110]. Besides the cadherins/catenins, multiple other signaling and adhesion molecules are involved in niche regulation such as SCF/c-Kit, Jagged/Notch, angiopoietin-1/Tie2 (Ang-1/Tie2), and $\mathrm{Ca}^{2+}$-sensing receptor (CaR) [111,112].

\section{Strategies to Eradicate CSC}

As highly differentiated cells that rarely divide, and as rapidly proliferating cells that have poorly differentiated phenotypes, two basic therapeutic approaches for combatting cancer have developed: "differentiation therapy" [113] to induce differentiation and "destruction therapy" [114] to thwart malignant proliferation. Although the suggested therapeutic strategies are theoretically promising, the limited success in some cases encouraged the researchers and clinicians to propose a new strategy to eradicate CSC.

The concept of CSC helps to explain why treatments that substantially reduce the tumor mass by removing proliferating cells fail to cure patients, because CSC are usually slow cycling and, therefore, resistant to the conventional treatments in addition to displaying enhanced DNA repair [115,116] and asynchronous DNA synthesis [117]. In addition, SC expresses higher levels of anti-apoptotic proteins such as members of the Bcl-2 family. Further, most CSC express high levels of multiple drug resistance proteins (MDR) and, thus, are able to pump out many chemotherapeutic drugs. Lastly, effective immunologic reactions to cancer antigens may only target differentiating tumor progeny whereas CSC most often do not express tumor markers and are therefore not attacked by the immune system. If CSC comprises only a minor fraction of total tumor cells and if these cells drive tumorigenesis, then profiling of purified populations of CSC may

Figure 3. Schematic overview of signaling pathways that can function as therapeutic target MSC. Therapeutic strategies for the efficient treatment of melanoma metastasis. The inhibition of Sonic Hedgehog (Shh) ligand to bind to its receptor Patched 1 (Ptch1) by the Shh ligand inhibitors leads to the repression of the smoothened (Smo) that becomes unable to promote the activation of Gli proteins (Gli1/2) that can not be translocated the nucleus , where they can function as transcriptional activators of their target genes that are essential for self-renewal of tumor-initiating cells/MSCs. Also, direct inhibition of Smo by Smo antagonists can inhibit self-renewal of MSC. The neutralization of Wnt ligand by Wnt ligand inhibitors leads to the suppression of Wnt pathway that, in turn, inhibits tumor progression. The inhibition of tyrosine kinase receptors such as EGF by tyrosine kinase inhibitors, integrins by integrin inhibitors, or Targeting of Notch pathway by anti-DLL4 antibody or with $\gamma$-secretase inhibitors can be an efficient strategies to eradicate MSCs.

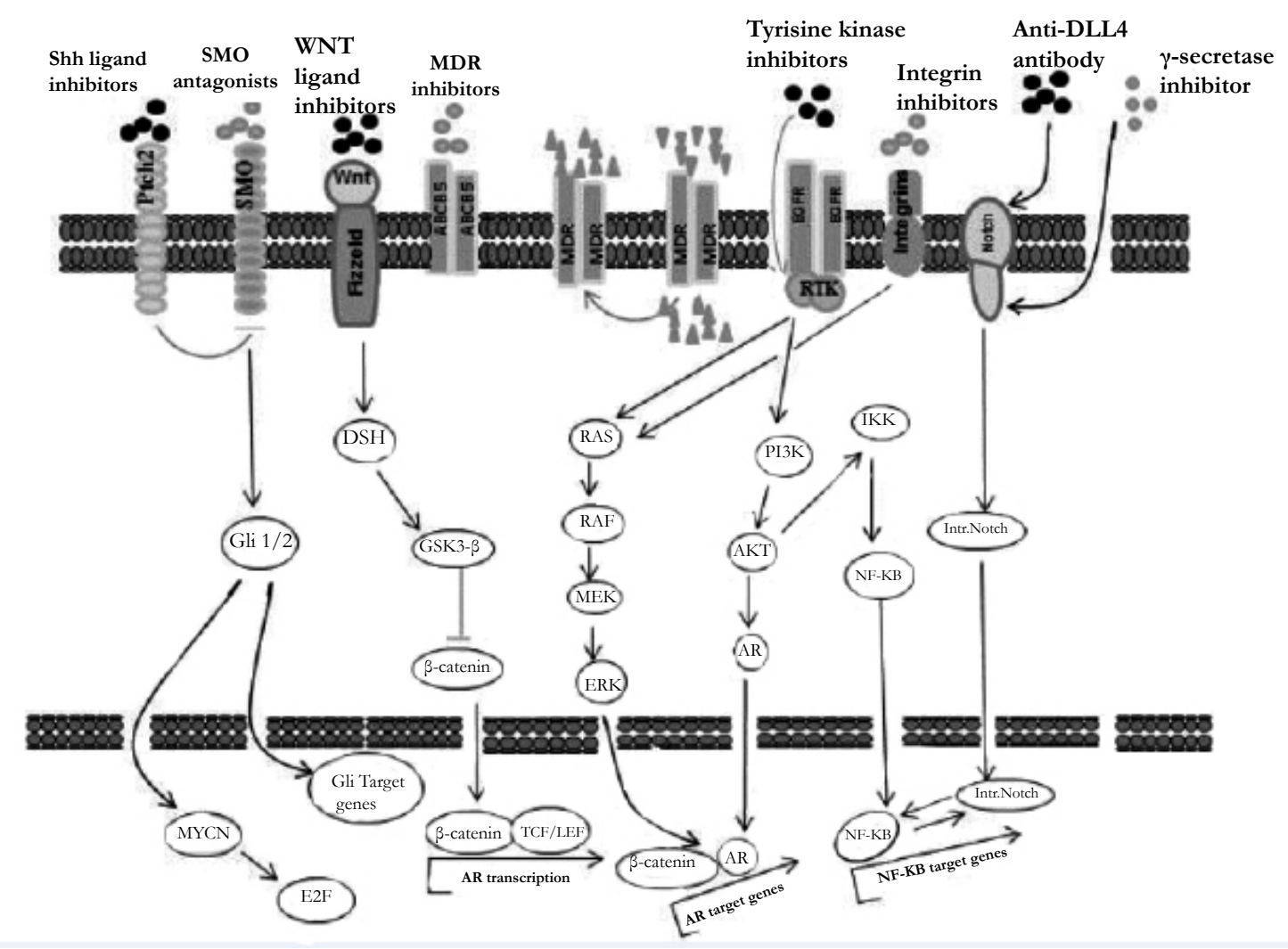


identify more successful molecular targets than profiling the bulge of the tumor. In this regard, a cancer signature of 11-genes has been shown to be under the control of the SC self-renewal gene Bmi-1 [118]. This conserved Bmi-1-driven pathway correlated with earlier recurrence, distant metastases and death in 1153 cancer patients based on the analysis of 11 genes [118]. From this and other studies, diverse hormones, growth factors, cytokines and chemokines (androgens, estrogens, EGF and TGF--catenin, Notch, BMP4, TGF--1/CXCR4) and tumorigenic signaling elements (telomerase, PI3K/AKT, NF-kB and Myc-1) have been suggested as important therapeutic targets to tackle initiation and progression of various cancers [119-121]. Therefore, it is becoming increasingly clear that effective cancer therapeutics may have to be retargeted to CSC.

Although the significant regression of bulky tumor lesions in response of patients to the treatment with inhibitors specific to BRAF, in addition to tumor recurrence many of melanoma patients develop resistance to treatments [122,123]. Therefore, the development of therapeutic strategies based on the combination of multi-modal therapeutic modalities that specifically trigger the destruction multiple pathways that are responsible for the maintenance of the bulk of the tumor with inhibitors that can trigger multiple pathways that are specific for melanoma subpopulation may be essential to prolonged dieses free survival melanoma patients. However, the profile of melanoma patients before and after therapy may help determine and optimize the best combination therapeutic strategy for the treatment of individual melanoma patients. Thus, the analysis of drug resistant melanoma subpopulations that are selected after therapy for epigenetic and or phenotypic alterations may help design personalized therapeutic approach for the treatment of individual patients. Figure 3 outlines signaling pathways and their possible targets as therapeutic strategies to eradicate MSC.

\section{Conclusion}

Malignant melanoma is a highly aggressive and heterogeneous tumor that composed of many subpopulations with unique genotypic and phenotypic pattern. The progression, maintenance, resistance to chemo- and radiotherapy, and recurrence of melanoma is attributed to small fraction of melanoma subpopulation that is similar to adult stem cells in characteristic and behavior. The identification of melanoma stem cells (MSCs) improved our knowledge regarding melanoma initiation, progression resistance, and recurrence. The improvement of current therapeutic strategies and/or their substitution by more efficient one, may help to improve the treatment outcome of melanoma. The investigation of the molecular mechanisms, which are responsible for the regulation of tumor progression, resistance and recurrence are attributed to MSCs. Understanding these mechanisms will help identify unique and/or multiple pathways that may be a potential target for melanoma treatment. The destruction or excessive activation of these pathways by small molecules inhibitors will help not only to eradicate the tumor bulk, but also will help eliminate melanoma-initiating cells. The ability to design therapeutic strategies based on elimination of both tumor bulk and MSCs is urgently needed for an efficient treatment of malignant melanoma.

\section{References}

[1]. Lavery DL, Nicholson AM, Poulsom R, Jeffery R, Hussain A et al. (2014) The stem cell organisation, and the proliferative and gene expression profile of Barrett's epithelium, replicates pyloric-type gastric glands. Gut.[In Press]
[2]. Vicente-Dueñas C, Hauer J, Ruiz-Roca L, Ingenhag D, Rodríguez-Meira A et al. (2014) Tumoral stem cell reprogramming as a driver of cancer: Theory, biological models, implications in cancer therapy. Semin Cancer Biol. [In Press]

[3]. Csermely P, Hódsági J, Korcsmáros T, Módos D, Perez-Lopez AR et al. (2014) Cancer stem cells display extremely large evolvability: alternating plastic and rigid networks as a potential Mechanism: Network models, novel therapeutic target strategies, and the contributions of hypoxia, inflammation and cellular senescence. Semin Cancer Biol. [In Press].

[4]. Griessinger E, Anjos-Afonso F, Pizzitola I, Rouault-Pierre K, Vargaftig J et al. (2014) A niche-like culture system allowing the maintenance of primary human acute myeloid leukemia-initiating cells: a new tool to decipher their chemoresistance and self-renewal mechanisms. Stem Cells Transl Med. 3: 520-9.

[5]. Matsuda S, Yan T, Mizutani A, Sota T, Hiramoto Y et al. (2014) Cancer stem cells maintain a hierarchy of differentiation by creating their niche. Int J Cancer 135: 27-36.

[6]. Ma R, Minsky N, Morshed SA, Davies TF (2014) Stemness in human thyroid cancers and derived cell lines: the role of asymmetrically dividing cancer stem cells resistant to chemotherapy. J Clin Endocrinol Metab. 99: E400-9.

[7]. Xin HW, Hari DM, Mullinax JE, Ambe CM, Koizumi T et al. (2012) Tumor-initiating label-retaining cancer cells in human gastrointestinal cancers undergo asymmetric cell division. Stem Cells. 30: 591-8.

[8]. Patrawala L, Calhoun T, Schneider-Broussard R, Zhou J, Claypool K et al. (2005) Side population is enriched in tumorigenic, stem-like cancer cells, whereas ABCG2+ and ABCG2- cancer cells are similarly tumorigenic. Cancer Res. 65: 6207-19.

[9]. Shekhani MT, Jayanthy AS, Maddodi N, Setaluri V (2013) Cancer stem cells and tumor transdifferentiation: implications for novel therapeutic strategies. Am J Stem Cells. 2: 52-61.

[10]. Yu CC, Chang YC (2013) Enhancement of cancer stem-like and epithelial-mesenchymal transdifferentiation property in oral epithelial cells with long-term nicotine exposure: reversal by targeting SNAIL. Toxicol Appl Pharmacol. 266: 459-69.

[11]. Sarvi S, Mackinnon AC, Avlonitis N, Bradley M, Rintoul RC et al. (2014) CD133+ cancer stem-like cells in small cell lung cancer are highly tumorigenic and chemoresistant but sensitive to a novel neuropeptide antagonist. Cancer Res. 74: 1554-65.

[12]. Papagerakis S, Pannone G, Zheng L, About I, Taqi N et al. (2014) Oral epithelial stem cells-Implications in normal development and cancer metastasis. Exp Cell Res. pii: S0014-4827.

[13]. Czyz M, Koprowska K, Sztiller-Sikorska M (2013) Parthenolide reduces the frequency of $\mathrm{ABCB}$-positive cells and clonogenic capacity of melanoma cells from anchorage independent melanospheres. Cancer Biol Ther. 14: $135-45$.

[14]. Samaniego R, Estecha A, Relloso M, Longo N, Escat JL et al. (2013) Mesenchymal contribution to recruitment, infiltration, and positioning of leukocytes in human melanoma tissues. J Invest Dermatol. 133: 2255-64

[15]. Gazzaniga P, Cigna E, Panasiti V, Devirgiliis V, Bottoni U et al. (2010) CD133 and ABCB5 as stem cell markers on sentinel lymph node from melanoma patients. Eur J Surg Oncol. 36:1211-4.

[16]. Prasmickaite L, Engesaeter BØ, Skrbo N, Hellenes T, Kristian A et al. (2010) Aldehyde dehydrogenase (ALDH) activity does not select for cells with enhanced aggressive properties in malignant melanoma. PLoS One. 5: e10731.

[17]. El-Khattouti A, Selimovic D, Haïkel Y, Megahed M, Gomez CR et al. (2014) Identification and analysis of CD133(+) melanoma stem-like cells conferring resistance to taxol: An insight into the mechanisms of their resistance and response. Cancer Lett. 343: 123-33.

[18]. Ramgolam K, Lauriol J, Lalou C, Lauden L, Michel L et al. (2011) Melanoma spheroids grown under neural crest cell conditions are highly plastic migratory/invasive tumor cells endowed with immunomodulator function. PLoS One. 6: e18784.

[19]. Santini R, Pietrobono S, Pandolfi S, Montagnani V, D'Amico et al. (2014) SOX2 regulates self-renewal and tumorigenicity of human melanoma-initiating cells. ncogene. 2014 [In Press]

[20]. Sette G, Fecchi K, Salvati V, Lotti F, Pilozzi E et al. (2013) Mek inhibition results in marked antitumor activity against metastatic melanoma patientderived melanospheres and in melanosphere-generated xenografts. J Exp Clin Cancer Res. 32: 91.

[21]. Krelin Y, Berkovich L, Amit M, Gil Z (2013) Association between tumorigenic potential and the fate of cancer cells in a syngeneic melanoma model. PLoS One. 8: e62124.

[22]. Mo J, Sun B, Zhao X, Gu Q, Dong X et al. (2013) The in-vitro spheroid culture induces a more highly differentiated but tumorigenic population from melanoma cell lines. Melanoma Res. 23: 254-63.

[23]. Fukunaga-Kalabis M, Martinez G, Nguyen TK, Kim D, Santiago-Walker A et al. (2010) Tenascin-C promotes melanoma progression by maintaining the ABCB5-positive side population. Oncogene 29: 6115-24. 
[24]. Magnoni C, Giudice S, Pellacani G, Bertazzoni G, Longo C et al. (2014) Stem cell properties in cell cultures from different stage of melanoma progression. Appl Immunohistochem Mol Morphol. 22: 171-81.

[25]. Akiyama M, Matsuda Y, Ishiwata T, Naito Z, Kawana S (2013) Inhibition of the stem cell marker nestin reduces tumor growth and invasion of malignant melanoma. J Invest Dermatol. 133:1384-7.

[26]. Mihic-Probst D, Kuster A, Kilgus S, Bode-Lesniewska B, Ingold-Heppner B et al. (2007) Consistent expression of the stem cell renewal factor BMI-1 in primary and metastatic melanoma. Int J Cancer 121:1764-70.

[27]. de Oliveira Niero EL, Rocha-Sales B, Lauand C, Cortez BA, de Souza MM et al. (2014) The multiple facets of drug resistance: one history, different approaches. J Exp Clin Cancer Res. 33: 37.

[28]. Lowe GC, Saavedra A, Reed KB, Velazquez AI, Dronca RS et al. (2014) Increasing incidence of melanoma among middle-aged adults: an epidemiologic study in Olmsted County, Minnesota. Mayo Clin Proc. 89: 52-9.

[29]. Guo J, Si L, Kong Y, Flaherty KT, Xu X et al. (2011) Phase II, open-label, single-arm trial of imatinib mesylate in patients with metastatic melanoma harboring c-Kit mutation or amplification. J Clin Oncol. 29: 2904-9.

[30]. Weinstock MA (2006) Progress and prospects on melanoma: the way forward for early detection and reduced mortality. Clin Cancer Res. 12: 2297s-2300s.

[31]. Ma MW, Qian M, Lackaye DJ, Berman RS, Shapiro RL et al. (2012) Challenging the current paradigm of melanoma progression: brain metastasis as isolated first visceral site. Neuro Oncol. 14: 849-58.

[32]. Charles M. Balch, Jeffrey E. Gershenwald, Seng-jaw Soong et al. (2009) AJCC Melanoma Staging and Classification.J Clin Oncol. 27: 6199-6206.

[33]. Viros A, Fridlyand J, Bauer J, Lasithiotakis K, Garbe C et al. (2008) Improving Melanoma Classification by Integrating Genetic and Morphologic Features. PLoS Med. 5: e120

[34]. Virador VM, Muller J, Wu X, Abdel-Malek ZA, Yu ZX et al. (2002) Influence of alpha-melanocyte-stimulating hormone and ultraviolet radiation on the transfer of melanosomes to keratinocytes. FASEB J. 16: 105-7.

[35]. Shih IM, Elder DE, Hsu MY, Herlyn M (1994) Regulation of Mel-CAM/ MUC18 expression on melanocytes of different stages of tumor progression by normal keratinocytes. Am J Pathol. 145: 837-45.

[36]. Virchow R. (1855) Editorial. Arch Pathol Anat Physiol Klin Med 8: 23.

[37]. Cohnheim J. (1867) Ueber Entzuendung und Eiterung. Arch Pathol Anat Physiol Klin Med 40: 1-79.

[38]. Cohnheim J. (1875) Congenitales. Quergestreiftes Muskelsarkom der Nieren. Virchow's Arch 65: 64.

[39]. Durante F. (1874) Nesso fisio-pathologico tra la strutura dei nei materni e la genesi di alcuni tumori maligni. Arch Memori Osservaz Chir Pract 11: 217-26.

[40]. Lapidot T, Sirard C, Vormoor J (1994) A cell initiating human acute myeloid leukaemia after transplantation into SCID mice. Nature 367: 645-8.

[41]. Al-Hajj M, Wicha MS, Benito-Hernandez A, Morrison SJ, Clarke MF (2003) Prospective identification of tumorigenic breast cancer cells. Proc Natl Acad Sci USA 100: 3983-8.

[42]. Hope KJ, Jin L, Dick JE. (2004). Acute myeloid leukemia originates from a hierarchy of leukemic stem cell classes that differ in self-renewal capacity. Nat Immunol 5: 738-43.

[43]. Singh SK, Hawkins C, Clarke ID, Squire JA, Bayani J et al. (2004). Identification of human brain tumour initiating cells. Nature 432: 396-401.

[44]. Bapat SA1, Mali AM, Koppikar CB, Kurrey NK (2005) Stem and progenitor-like cells contribute to the aggressive behavior of human epithelial ovarian cancer. Cancer Res 65: 3025-9.

[45]. Kim CF, Jackson EL, Woolfenden AE, Lawrence S, Babar I et al. (2005). Identification of bronchioalveolar stem cells in normal lung and lung cancer. Cell 121: 823-35.

[46]. O'Brien CA, Pollett A, Gallinger S, Dick JE(2007). A human colon cancer cell capable of initiating tumour growth in immunodeficient mice. Nature 445: 106-10.

[47]. Ricci-Vitiani L, Lombardi DG, Pilozzi E, Biffoni M, Todaro M et al.(2007). Identification and expansion of human colon-cancer-initiating cells. Nature 445: 111-5.

[48]. Prince ME, Sivanandan R, Kaczorowski A, Wolf GT, Kaplan MJ et al. (2007) Identification of a subpopulation of cells with cancer stem cell properties in head and neck squamous cell carcinoma. Proc Natl Acad Sci USA 104: 973-8.

[49]. Collins AT, Berry PA, Hyde C (2005) Prospective identification of tumorigenic prostate cancer stem cells. Cancer Res 65: 10946-51.

[50]. Tedder TF, Engel P. (1994) CD20: a regulator of cell-cycle progression of B lymphocytes. Immunol Today 15: 450-4.

[51]. Fang D, Nguyen TK, Leishear K, Finko R, Kulp AN et al. (2005) A tumorigenic subpopulation with stem cell properties in melanomas. Cancer Res 65: 9328-37.

[52]. Schatton T, Murphy GF, Frank NY, Yamaura K, Waaga-Gasser AM et al. (2008) Identification of cells initiating human melanomas. Nature 451: 345-9.

[53]. Kupas V, Weishaupt C, Siepmann D, Kaserer ML, Eickelmann M et al.
(2011) RANK is expressed in metastatic melanoma and highly upregulated on melanoma-initiating cells. J Invest Dermatol 131: 944-55.

[54]. Kumar S, Sharma P, Kumar D, Chakraborty G, Gorain M et al. (2013) Functional characterization of stromal osteopontin in melanoma progression and metastasis. PLoS One 8: e69116.

[55]. Anichini A, Fossati G, Parmiani G (1986) Heterogeneity of clones from a human metastatic melanoma detected by autologous cytotoxic $\mathrm{T}$ lymphocyte clones. J Exp Med. 163: 215-20.

[56]. Thurber AE, Douglas G, Sturm EC, Zabierowski SE, Smit DJ et al. (2011) Inverse expression states of the BRN2 and MITF transcription factors in melanoma spheres and tumour xenografts regulate the NOTCH pathway. Oncogene 30: 3036-48

[57]. Dong C, Slattery MJ, Liang S, Peng HH (2005) Melanoma cell extravasation under flow conditions is modulated by leukocytes and endogenously produced interleukin 8. Mol Cell Biomech. 2: 145-59.

[58]. Lugassy C, Dickersin GR, Christensen L, Karaoli T, LeCharpentier M et al. (1999) Ultrastructural and immunohistochemical studies of the periendothelial matrix in human melanoma: evidence for an amorphous matrix containing laminin.J Cutan Pathol. 26:78-83.

[59]. Braeuer RR, Watson IR, Wu CJ, Mobley AK, Kamiya T et al. (1999) Tumor microvessels in melanoma express the beta-2 chain of laminin. Implications for melanoma metastasis. J Cutan Pathol. 26: 222-6.

[60]. Baccelli I, Trumpp A (2012) The evolving concept of cancer and metastasis stem cells. J Cell Biol.: 198:281-93.

[61]. Ksiązikiewicz M, Markiewicz A, Zaczek AJ (2012) Epithelial-mesenchymal transition: a hallmark in metastasis formation linking circulating tumor cells and cancer stem cells. Pathobiology. 79: 195-208.

[62]. Ramakrishna R, Rostomily R (2013) Seed, soil, and beyond: The basic biology of brain metastasis. Surg Neurol Int. 4: S256-64.

[63]. Civenni G, Sommer L (2009) Chemokines in neuroectodermal development and their potential implication in cancer stem cell-driven metastasis. Semin Cancer Biol. 19: 68-75.

[64]. Jin Y, Mao J, Wang H, Hou Z, Ma W et al. (2013) Enhanced tumorigenesis and lymphatic metastasis of CD133+ hepatocarcinoma ascites syngeneic cell lines mediated by JNK signaling pathway in vitro and in vivo. Biomed Pharmacother. 67: 337-45.

[65]. Ogasawara MA, Zhang H (2009) Redox regulation and its emerging roles in stem cells and stem-like cancer cells. Antioxid Redox Signal. 11: 110722.

[66]. Yu Y, Shi X, Shu Z, Xie T, Huang K et al. (2014) Stromal cell-derived factor-1 (SDF-1)/CXCR4 axis enhances cellular invasion in ovarian carcinoma cells via integrin $\beta 1$ and $\beta 3$ expressions. Oncol Res. 21: 217-25.

[67]. Wang RF, Zhang LH, Shan LH, Sun WG, Chai CC et al. (2013) Effects of the fibroblast activation protein on the invasion and migration of gastric cancer. Exp Mol Pathol. 95: 350-56.

[68]. Kim KH, Seol HJ, Kim EH, Rheey J, Jin HJ et al. (2013) Wnt/ß-catenin signaling is a key downstream mediator of MET signaling in glioblastoma stem cells. Neuro Oncol. 15: 161-71.

[69]. Watt FM, Collins CA (2008) Role of beta-catenin in epidermal stem cell expansion, lineage selection, and cancer. Cold Spring Harb Symp Quant Biol. 73:503-12.

[70]. Yang PT, Anastas JN, Toroni RA, Shinohara MM, Goodson JM (2012) WLS inhibits melanoma cell proliferation through the $\beta$-catenin signalling pathway and induces spontaneous metastasis. EMBO Mol Med. 4:1294307

[71]. Rappa G, Mercapide J, Anzanello F, Le TT, Johlfs MG et al. (2013) Wnt interaction and extracellular release of prominin-1/CD133 in human malignant melanoma cells. Exp Cell Res. 319: 810-9.

[72]. Dissanayake SK, Wade M, Johnson CE, O'Connell MP, Leotlela PD et al. (2007) The Wnt5A/protein kinase C pathway mediates motility in melanoma cells via the inhibition of metastasis suppressors and initiation of an epithelial to mesenchymal transition. J Biol Chem. 282: 17259-71.

[73]. Peppicelli S, Bianchini F, Torre E, Calorini L (2014) Contribution of acidic melanoma cells undergoing epithelial-to-mesenchymal transition to aggressiveness of non-acidic melanoma cells. Clin Exp Metastasis. 2014 [In Press].

[74]. Fenouille N, Tichet M, Dufies M, Pottier A, Mogha A et al. (2012) The epithelial-mesenchymal transition (EMT) regulatory factor SLUG (SNAI2) is a downstream target of SPARC and AKT in promoting melanoma cell invasion. PLoS One. 7: e40378.

[75]. Kreiseder B, Orel L, Bujnow C, Buschek S, Pflueger M et al. (2013) $\alpha$-Catulin downregulates E-cadherin and promotes melanoma progression and invasion. Int J Cancer. 132: 521-30.

[76]. Vaid M, Prasad R, Sun Q, Katiyar QS (2010) Silymarin Targets $\beta$-Catenin Signaling in Blocking Migration/Invasion of Human Melanoma Cells. PLoS One. 6: e23000.

[77]. Ria R, Reale A, Castrovilli A, Mangialardi G, Dammacco F et al. (2010) Angiogenesis and progression in human melanoma. Dermatol Res Pract. 2010:185687.

[78]. Ye S, Dhillon S, Turner SJ, Bateman AC, Theaker JM, Pickering RM et 
al. (2001) Invasiveness of cutaneous malignant melanoma is influenced by matrix metalloproteinase 1 gene polymorphism. Cancer Res. 61:1296-8.

[79]. Lallas A, Kyrgidis A, Ferrara G, Kittler H, Apalla Z et al. (2014) Atypical Spitz tumours and sentinel lymph node biopsy: a systematic review. Lancet Oncol. 15: e178-83.

[80]. Kahlert UD, Maciaczyk D, Doostkam S, Orr BA, Simons B et al. (2012) Activation of canonical WNT/ $\beta$-catenin signaling enhances in vitro motility of glioblastoma cells by activation of ZEB1 and other activators of epithelial-to-mesenchymal transition. Cancer Lett. 325: 42-53.

[81]. Takenaga M, Tamamura H, Hiramatsu K, Nakamura N, Yamaguchi Yet al. (2004) A single treatment with microcapsules containing a CXCR4 antagonist suppresses pulmonary metastasis of murine melanoma. Biochem Biophys Res Commun. 320: 226-32.

[82]. Scala S, Ottaiano A, Ascierto PA, Cavalli M, Simeone E, Giuliano P, Napolitano M, Franco R, Botti G, Castello G (2005) Expression of CXCR4 predicts poor prognosis in patients with malignant melanoma. Clin Cancer Res. 11:1835-41.

[83]. Rodini CO, Suzuki DE, Nakahata AM, Pereira MC, Janjoppi L et al. (2010) Aberrant signaling pathways in medulloblastomas: a stem cell connection. Arq Neuropsiquiatr. 68: 947-52

[84]. Jazirehi AR, Nazarian R, Torres-Collado AX, Economou JS (2014) Aberrant apoptotic machinery confers melanoma dual resistance to BRAF(V600E) inhibitor and immune effector cells: immunosensitization by a histone deacetylase inhibitor. Am J Clin Exp Immunol. 3: 43-56.

[85]. Nickoloff BJ, Hendrix MJ, Pollock PM, Trent JM, Miele L et al. (2005) Notch and NOXA-related pathways in melanoma cells. J Investig Dermatol Symp Proc. 10: 95-104.

[86]. Mathieu MG, Miles AK, Ahmad M, Buczek ME, Pockley AG et al., (2014) The helicase HAGE prevents interferon- $\alpha$-induced PML expression in $\mathrm{ABCB} 5+$ malignant melanoma-initiating cells by promoting the expression of SOCS1. Cell Death Dis. 5:e1061.

[87]. Chen KG, Valencia JC, Gillet JP, Hearing VJ, Gottesman MM (2009) Involvement of $\mathrm{ABC}$ transporters in melanogenesis and the development of multidrug resistance of melanoma. Pigment Cell Melanoma Res. 22:740-9.

[88]. Suryo Rahmanto Y, Dunn LL, Richardson DR (2007) Identification of distinct changes in gene expression after modulation of melanoma tumor antigen p97 (melanotransferrin) in multiple models in vitro and in vivo. Carcinogenesis. 28:2172-83

[89]. Vásquez-Moctezuma I, Meraz-Ríos MA, Villanueva-López CG, Magaña M, Martínez-Macias R et al. (2010) ATP-binding cassette transporter $\mathrm{ABCB} 5$ gene is expressed with variability in malignant melanoma.Actas Dermosifiliogr 101: 341-8.

[90]. Morrison R, Schleicher SM, Sun Y, Niermann KJ, Kim S et al. (2011) Targeting the mechanisms of resistance to chemotherapy and radiotherapy with the cancer stem cell hypothesis. J Oncol. 2011:941876.

[91]. Kim Y, Joo KM, Jin J, Nam DH (2009) Cancer Stem Cells and Their Mechanism of Chemo-Radiation Resistance. Int J Stem Cells. 2: 109-114.

[92]. Bleau AM, Agliano A, Larzabal L, Lopez A, Calvo A (2014) Metastatic dormancy: a complex network between cancer stem cells and their microenvironment. Histol Histopathol. [In Press].

[93]. Wang WJ, Wu SP, Liu JB, Shi YS, Huang X et al. (2013) MYC regulation of $\mathrm{CHK} 1$ and $\mathrm{CHK} 2$ promotes radioresistance in a stem cell-like population of nasopharyngeal carcinoma cells. Cancer Res. 73: 1219-31.

[94]. Demidenko ZN, Halicka D, Kunicki J, McCubrey JA, Darzynkiewicz $\mathrm{Z}$ et al. (2005) Selective killing of adriamycin-resistant (G2 checkpointdeficient and MRP1-expressing) cancer cells by docetaxel. Cancer Res. 65: 4401-7.

[95]. Ropolo M, Daga A, Griffero F, Foresta M, Casartelli G et al. (2009) Comparative analysis of DNA repair in stem and nonstem glioma cell cultures. Mol Cancer Res. 7: 383-92.

[96]. Ray-David H, Romeo Y, Lavoie G, Déléris P, Tcherkezian J et al. (2013) RSK promotes G2 DNA damage checkpoint silencing and participates in melanoma chemoresistance. Oncogene. 32: 4480-9.

[97]. Chen KG, Valencia JC, Gillet JP, Hearing VJ, Gottesman MM (2009) Involvement of $\mathrm{ABC}$ transporters in melanogenesis and the development of multidrug resistance of melanoma. Pigment Cell Melanoma Res. 22: 740-9.

[98]. Luo Y, Ellis LZ, Dallaglio K, Takeda M, Robinson WA et al. (2012) Side population cells from human melanoma tumors reveal diverse mechanisms for chemoresistance. J Invest Dermatol. 132: 2440-50.

[99]. Shimura T, Noma N, Oikawa T, Ochiai Y, Kakuda S et al. (2012) Activa- tion of the AKT/cyclin D1/Cdk4 survival signaling pathway in radioresistant cancer stem cells. Oncogenesis. 1: e12.

[100]. Giancotti FG (2013) Mechanisms governing metastatic dormancy and reactivation. Cell. 155: 750-64.

[101]. Stewart DJ, Wallace S, Feun L, Leavens M, Young SE et al. (1982) A phase I study of intracarotid artery infusion of cis-Diamminedichloroplatinum(II) in patients with recurrent malignant intracerebral tumors. Cancer Res. 42: 2059-62.

[102]. Koukourakis MI, Giatromanolaki A, Tsakmaki V, Danielidis V, Sivridis E (2012) Cancer stem cell phenotype relates to radio-chemotherapy outcome in locally advanced squamous cell head-neck cancer. Br J Cancer. 106: 84653.

[103]. Luan Q, Sun J, Li C, Zhang G, Lv Y et al. (2011) Mutual enhancement between heparanase and vascular endothelial growth factor: a novel mechanism for melanoma progression. Cancer Lett. 308: 100-11.

[104]. Das AM, Seynhaeve AL, Rens JA, Vermeulen CE, Koning GA et al. (2014) Differential TIMP3 expression affects tumor progression and angiogenesis in melanomas through regulation of directionally persistent endothelial cell migration. Angiogenesis. 17:163-77.

[105]. Weiss MB, Abel EV, Mayberry MM, Basile KJ, Berger AC et al. (2012) TWIST1 is an ERK1/2 effector that promotes invasion and regulates MMP-1 expression in human melanoma cells. Cancer Res. 72: 6382-92.

[106]. Kato T, Suetake T, Kumasaka N, Tabata N, Sugiyama Y et al. (1995) Nodular melanoma in 62 Japanese patients: influence of initial surgical treatment on local recurrence and prognosis. J Dermatol. 22:723-8.

107]. Fusi S, Ariyan S, Sternlicht A (1993) Data on first recurrence after treatment for malignant melanoma in a large patient population. Plast Reconstr Surg. 91: 94-8

[108]. Tumbar T, Guasch G, Greco V, Blanpain C, Lowry WE et al. (2004) Defining the epithelial stem cell niche in skin. Science 303: 359-63.

[109]. Fuchs E, Tumbar T, Guasch G. (2004) Socializing with the neighbors: stem cells and their niche. Cell 116: 769-78.

[110]. Lowry WE, Blanpain C, Nowak JA, Guasch G, Lewis L et al. (2005) Defining the impact of beta-catenin/Tcf transactivation on epithelial stem cells. Genes Dev 19: 1596-611.

[111]. Heissig B, Hattori K, Dias S, Friedrich M, Ferris B et al. (2002). Recruitment of stem and progenitor cells from the bone marrow niche requires MMP-9 mediated release of kit-ligand. Cell 109: 625-37.

[112]. Calvi LM1, Adams GB, Weibrecht KW, Weber JM, Olson DP et al. (2003). Osteoblastic cells regulate the haematopoietic stem cell niche. Nature 425: 841-6.

[113]. Sell S. (2004). Stem cell origin of cancer and differentiation therapy. Crit Rev Oncol Hematol 51: 1-28.

[114]. Tubiana M, Malaise EP (1973). Cell proliferation kinetics of tumors and cancer treatment. Pathol Biol 21, 647-64.

[115]. Nuciforo P, Fraggetta F. (2004). Cancer stem cell theory: pathologists' considerations and ruminations about wasting time and wrong evaluations. J Clin Pathol 57, 782.

[116]. Bao S, Wu Q, McLendon RE, Hao Y, Shi Q et al. (2006). Glioma stem cells promote radioresistance by preferential activation of the DNA damage response. Nature 444, 756-60.

[117]. Rambhatla L, Ram-Mohan S, Cheng JJ, Sherley JL (2005). Immortal DNA strand cosegregation requires p53/IMPDH-dependent asymmetric self-renewal associated with adult stem cells. Cancer Res 65, 3155-61.

[118]. Glinsky GV, Berezovska O, Glinskii AB. (2005). Microarray analysis identifies a death-from-cancer signature predicting therapy failure in patients with multiple types of cancer. J Clin Invest 115, 1503-21.

[119]. Beachy PA, Karhadkar SS, Berman DM. (2004). Tissue repair and stem cell renewal in carcinogenesis. Nature 432, 324-31.

[120]. Reya T, Morrison SJ, Clarke MF, et al. (2001). Stem cells, cancer, and cancer stem cells. Nature 414, 105-11.

[121]. Mimeault M, Batra SK. (2006). Recent advances on multiple tumorigenic cascades involved in prostatic cancer progression and targeting therapies. Carcinogenesis 27, 1-22.

[122]. Lassen A, Atefi M, Robert L, Wong DJ, Cerniglia M et al. (2014) Effects of AKT inhibitor therapy in response and resistance to BRAF inhibition in melanoma. Mol Cancer. 13:83.

[123]. sabbatino F, Wang Y, Wang X, Flaherty KT, Yu L et al. (2014) PDGFRa up-regulation mediated by sonic hedgehog pathway activation leads to BRAF inhibitor resistance in melanoma cells with BRAF mutation. Oncotarget. 5:1926. 